\title{
PENDIDIKAN KARAKTER DAN EKSISTENSI PEMUDA
}

\author{
Arhanuddin Salim \\ Institut Agama Islam Negeri Manado, Manado, Indonesia \\ arhanuddin@yahoo.com
}

\begin{abstract}
To realize the vision of national development, namely to realize a society of noble character, morality, ethics, culture and civilization based on the Pancasila philosophy, the national education system must be the main focus that must be addressed. Based on the functions and objectives of national education, it is clear that education at every level must be organized systematically to achieve that goal. This concerns the reality of education in educational units from early childhood education to tertiary education which is currently experiencing fading and degradation in terms of forming the character of its students. All of this is due to the absence of a learning system focused on the direction of the formation of superior character values.
\end{abstract}

Keywords:education, character education, youth and the future of the nation

\begin{abstract}
Abstrak.Untuk mewujudkan visi pembangunan nasional, yaitu mewujudkan masyarakat berakhlak mulia, bermoral, beretika, berbudaya dan beradab berdasarkan falsafah Pancasila, maka sistem pendidikan nasional harus menjadi fokus utama yang harus dibenahi. Berdasarkan fungsi dan tujuan pendidikan nasional, jelas bahwa pendidikan di setiap jenjang, harus diselenggarakan secara sistematis guna mencapai tujuan tersebut. Hal ini menyangkut realitas pendidikan di dalam satuan pendidikan dari pendidikan usia dini sampai perguruan tinggi yang saat ini mengalami pemudaran dan degradasi dalam hal pembentukan karakter peserta didiknya. Semua ini disebabkan karena tidak adanya sistem pembelajaran yang terfokus pada arah pembentukan nilai-nilai karakter unggul.
\end{abstract}

Kata Kunci:pendidikan, pendidikankarakter, pemuda dan masa depanbangsa 
Pendahuluan

Wacana klasik yang selalu dijadikan titik tolak dalam membahas pendidikan dan pengajaran adalah pandangan yang menempatkan pendidikan itu sendiri sebagai suatu gejala individual di satu pihak, dan pandangan yang menempatkan pendidikan sebagai gejala sosial. ${ }^{1}$ Menurut pandangan pertama, pendidikan merupakan instrumen institusional bagi potensi dasar yang dimiliki oleh manusia, yaitu kemampuan dasar yang secara otomatis dapat berkembang. ${ }^{2}$ Kemudian dalam pandangan kedua, pendidikan diartikan sebagai proses pembudayaan nilai-nilai, ilmu pengetahuan dan keterampilan yang berkembang dalam masyarakat, maka fungsi fundamental yang harus dijalankan oleh pendidikan adalah menyediakan suatu suasana yang kondusif bagi pengembangan etos manusia sebagai pendidik. ${ }^{3}$

Indonesia memerlukan sumberdaya manusia dalam jumlah dan mutu yang memadai sebagai pendukung utama dalam pembangunan. Untuk memenuhi sumberdaya manusia tersebut,

${ }^{1}$ M. Arifin, Ilmu Pendidikan Islam: Suatu Tinjauan Teoritis dan Praktis Berdasarkan Pendekatan Interdisipliner, (Jakarta: Bumi Aksara, 1999), h. 5.

2 Ibid.

${ }^{3}$ Ibid., h. 9. Lihat juga Syamsul Arifin, Merambah Jalan Baru Dalam Beragama, (Yokgyakarta: Ittiqa' Press, 2000), h. 193. pendidikan memiliki peran yang sangat penting. Hal ini sesuai dengan UU No 20 Tahun 2003 Tentang Sistem Pendidikan Nasional pada Pasal 3, yang menyebutkan bahwa "pendidikan nasional berfungsi mengembangkan kemampuan dan membentuk karakter serta peradaban bangsa yang bermartabat dalam rangka mencerdaskan kehidupan bangsa". Pendidikan nasional bertujuan untuk "mengembangkan potensi peserta didik agar menjadi manusia yang beriman dan bertakwa kepada Tuhan Yang Maha Esa, berakhlak mulia, sehat, berilmu, cakap, kreatif, mandiri, dan menjadi warga negara yang demokratis serta bertanggung jawab".4 Pendidikan karakter merupakan perwujudan amanat Pancasila dan Pembukaan UUD 1945, dilatarbelakangi oleh realitas permasalahan kebangsaan yang berkembang saat ini, seperti: bergesernya nilai etika dalam kehidupan berbagsa dan bernegara; memudarnya kesadaran terhadap nilai-nilai Pancasila; memudarnya kesadaran terhadap nilainilai budaya bangsa; ancaman disintegrasi bangsa; dan melemahnya

${ }^{4}$ Pemerintah Republik Indonesia, UndangUndang Sisdiknas (Sistem Pendidikan Nasional) 2003 (UU RI No. 20 Th. 2003)., (Jakarta: Sinar Grafika, 2005), h. 20. 
kemandirian bangsa. ${ }^{5}$ Untuk mendukung realisasi (perwujudan) cita-cita pembangunan karakter sebagaimana diamanatkan dalam Pancasila dan Pembukaan UUD 1945 serta mengatasi permasalahan kebangsaan ini, maka pemerintah menjadikan pembangunan karakter sebagai salah satu program prioritas pembangunan nasional. Semangat itu secara implisit ditengaskan dalam rencana Pembangunan Jangka Panjang Nasional (RNJP) tahun 20052025, di mana pembangunan karakter ditempatkan sebagai landasan untuk mewujudkan visi pembangunan nasional, yaitu mewujudkan masyarakat berakhlak mulia, bermoral, beretika, berbudaya dan beradab berdasarkan falsafah Pancasila. Berdasarkan fungsi dan tujuan pendidikan nasional, jelas bahwa pendidikan di setiap jenjang, harus diselenggarakan secara sistematis guna mencapai tujuan tersebut. Hal ini menyangkut realitas pendidikan di dalam satuan pendidikan dari pendidikan usia dini sampai perguruan tinggi yang saat ini mengalami pemudaran dan degradasi dalam hal pembentukan karakter peserta didiknya. Semua ini disebabkan karena tidak adanya sistem pembelajaran yang terfokus pada arah pembentukan nilai-

${ }^{5}$ Buku Induk Kebijakan Nasional Pembangunan Karakter Bangsa 2010-2025). nilai karakter unggul. Guru sebagai contoh di dalam proses pembelajaran tidak mampu mentransfer atau mengkostruksi nilai-nilai karakter tersebut di dalam setiap diri peserta didik. Kenyataan ini disebabkan karena beberapa guru hanya menganggap bahwa pekerjaan sebagai guru hanya sebatas mendapatkan penghasilan untuk memenuhi kebutuhan sehari-hari, beberapa guru hanya sekedar menghilangkan kewajiban dalam mengajar, menjadi guru tidak dipahami sebagai sebuah proses perjuangan suci untuk mencerdaskan kehidupan bangsa.

Kondisi ini mengakibatkan terputusnya bagian penting dalam pendidikan yakni terciptanya kondisi belajar yang menyenangkan dan membuat peserta didik mampu mengembangkan dirinya secara baik dan benar. Tidak adanya jalinan yang baik antara guru dan peserta didik, memungkinkan terciptanya kondisi yang membuat peserta didik tidak mampu menjadi insan paripurna yang berkarakter. Akhirnya kondisi ini membawa peserta didik pada keterpecahan psikologis seperti tidak peduli lingkungan, acak-acakan, tawuran, tidak jujur, tidak mampu bekerja keras, tidak disiplin dan karakter-karakter 
buruk lainya yang tidak bisa diharapkan menjadi pelanjut masa depan bangsa.

\section{Pentingnnya Pendidikan Karakter}

Penanganan secara dini tentang masalah tersebut berkaitan dengan pembentukan karakter peserta didik sehingga mampu bersaing, beretika, bermoral, sopan santun dan berinteraksi dengan masyarakat. Berdasarkan penelitian di Harvard University Amerika Serikat, ternyata kesuksesan seseorang tidak ditentukan semata-mata oleh pengetahuan dan kemampuan teknis (hard skill) saja, tetapi lebih oleh kemampuan mengelola diri dan orang lain (soft skill). Penelitian ini mengungkapkan, kesuksesan hanya ditentukan sekitar 20 persen oleh hard skill dan sisanya 80 persen oleh soft skill. Bahkan orang-orang tersukses di dunia bisa berhasil dikarenakan lebih banyak didukung kemampuan soft skill daripada hard skill. ${ }^{6}$ Hal ini mengisyaratkan bahwa mutu pendidikan karakter peserta didik sangat penting untuk ditingkatkan. Karakter merupakan nilai-nilai perilaku manusia yang berhubungan dengan Tuhan Yang Maha Esa, diri sendiri, sesama manusia, lingkungan, dan

${ }^{6}$ Ali Ibrahim Akbar, Teori Soft Skill dalam Mencapai Keberhasilah Hidup (Jakarta: Prestasi Pustaka, 2007), h. 22. kebangsaan yang terwujud dalam pikiran, sikap, perasaan, perkataan, dan perbuatan berdasarkan norma-norma agama, hukum, tata krama, budaya, dan adat istiadat.

Sebagai upaya untuk meningkatkan kesesuaian dan mutu pendidikan karakter, Kementerian Pendidikan Nasional mengembangkan grand design pendidikan karakter untuk setiap jalur, jenjang, dan jenis satuan pendidikan. Grand design menjadi rujukan konseptual dan operasional pengembangan, pelaksanaan, dan penilaian pada setiap jalur dan jenjang pendidikan. Konfigurasi karakter dalam konteks totalitas proses psikologis dan sosial-kultural tersebut dikelompokan dalam: Olah Hati (Spiritual and emotional development), Olah Pikir (intellectual development), Olah Raga dan Kinestetik (Physical and kinestetic development), dan Olah Rasa dan Karsa (Affective and Creativity development).7Pengembangan dan implementasi pendidikan karakter perlu dilakukan dengan mengacu pada grand design tersebut.Menurut UU No 20 Tahun 2003 Tentang Sistem Pendidikan Nasional pada Pasal 13 Ayat 1 menyebutkan bahwa Jalur pendidikan terdiri atas pendidikan formal, nonformal,

${ }^{7}$ Kusmiati Dkk., Dasar-Dasar Perilaku (Jakarta: Pusdiknakes, 2005), h. 57. 
dan informal yang dapat saling melengkapi dan memperkaya. Pendidikan informal adalah jalur pendidikan keluarga dan lingkungan. ${ }^{8}$ Pendidikan informal sesungguhnya memiliki peran dan kontribusi yang sangat besar dalam keberhasilan pendidikan. Peserta didik mengikuti pendidikan di sekolah hanya sekitar 7 jam per hari, atau kurang dari 30\%. Selebihnya (70\%), peserta didik berada dalam keluarga dan lingkungan sekitarnya. Jika dilihat dari aspek kuantitas waktu, pendidikan di sekolah berkontribusi hanya sebesar $30 \%$ terhadap hasil pendidikan peserta didik.

Selama ini, pendidikan informal terutama dalam lingkungan keluarga belum memberikan kontribusi berarti dalam mendukung pencapaian kompetensi dan pembentukan karakter peserta didik. Kesibukan dan aktivitas kerja orang tua yang relatif tinggi, kurangnya pemahaman orang tua dalam mendidik anak di lingkungan keluarga, pengaruh pergaulan di lingkungan sekitar, dan pengaruh media elektronik ditengarai bisa berpengaruh negatif terhadap perkembangan dan pencapaian hasil belajar peserta didik. Salah satu alternatif untuk mengatasi permasalahan tersebut adalah melalui pendidikan 25. karakter terpadu, yaitu memadukan dan mengoptimalkan kegiatan pendidikan informal lingkungan keluarga dengan pendidikan formal di sekolah. Dalam hal ini, waktu belajar peserta didik di sekolah perlu dioptimalkan agar peningkatan mutu hasil belajar, terutama pembentukan karakter peserta didik sesuai tujuan pendidikan dapat dicapai. Menurut Mochtar Buchori, pendidikan karakter seharusnya membawa peserta didik ke pengenalan nilai secara kognitif, penghayatan nilai secara afektif, dan akhirnya ke pengamalan nilai secara nyata. ${ }^{9}$

\section{Eksistensi Pemuda dan Masa depan Bangsa}

Mempelajari sejarah di banyak negara di dunia, maka kita akan banyak menemukan fakta bahwa pemuda adalah elemen utama yang melahirkan momenmomen penting dalam sejarah peradaban manusia dari masa yang lampau hingga ke masa yang kini. Hasan Al-Banna pernah mengatakan bahwa dalam setiap kebangkitan sebuah peradaban di belahan dunia manapun, maka kita akan menjumpai bahwa pemuda adalah salah satu irama rahasianya. Kita semua mahfum bahwa kemajuan suatu bangsa

${ }^{9}$ Mochtar Buchori, Menggugat Sistem Pendidikan; paradigma pendekatan holistic (Rajawali Press, Jakarta: 2007), h. 37. 
sangat ditentukan oleh kualitas pendidikannya dan masa depan bangsa berada di tangan generasi muda. Disinilah terlihat keterkaitan peran pemuda dalam pendidikan. Oleh karena itu masalah pendidikan nasional harus menjadi prioritas dalam pembangunan bangsa, dan penitikberatan fokus dan perhatian akan pelibatan kaum muda, menjadi hal yang krusial dalam proses kemajuan bangsa. Pentingnya pendidikan yang maju bagi generasi muda, karena mereka merupakan pondasi bangsa dan sebagai agent of change yang diharapkan mampu tampil untuk mewujudkan cita-cita bangsa yang telah dirintis oleh founding fathers termasuk dalam memajukan pendidikan.

Peran pemuda sangat besar sejak zaman pergerakan nasional Indonesia, dan dalam perjuangannya, banyak dilakukan melalui pendidikan bangsa. Tengoklah misalnya perjuangan Budi Oetomo, Taman Siswa dan lainnya. Para Founding Fathers pun banyak melakukan pendidikan bangsa, misalnya Soekarno yang tidak henti-hentinya mendidik bangsa, terutama untuk menumbuhkan kesadaran berbangsa, semangat nasionalisme dengan pendidikan politik dan yang juga dikenal dengan nation and character building. Harus dipahami bersama bahwa proses pendidikan bukan semata-mata menekankan pada aspek akademis, kecerdasan otak atau intelegensia saja. Namun, harus mencakup kecerdasan emosional dan kecerdasan spiritual. Bagi bangsa Indonesia, sedang dikembangkan pola pendidikan yang menitikberatkan pada pengembangan kepribadian yang bercirikan kebangsaan, yaitu pendidikan karakter yang bertujuan untuk meningkatkan mutu penyelenggaraan dan hasil pendidikan di sekolah, yang mengarah pada pencapaian pembentukan karakter dan akhlak mulia peserta didik secara utuh, terpadu, dan seimbang, sesuai standar kompetensi lulusan. Melalui pendidikan karakter diharapkan, pemuda mampu secara mandiri meningkatkan dan menggunakan pengetahuannya, mengkaji, dan menginternalisasi serta mempersonalisasi nilai-nilai karakter dan akhlak mulia sehingga terwujud dalam perilaku sehari-hari.

Pentingnya pendidikan karakter untuk pemuda dikuatkan dengan kenyataan bahwa pemuda-pemuda hari ini banyak yang mengalami krisis karakter. Tawuran antar pelajar atau antar mahasiswa, meningkatnya kenakalan remaja termasuk penyalahgunaan narkoba, maraknya pergaulan bebas, dan lain-lain, 
merupakan bukti nyata ambiguitas peran pendidikan nasional yang tidak memberikan nilai tambah dalam proses pembelajaran mereka. Belum lagi banyak sekali pemuda saat ini yang terjebak dalam lingkaran apatisme, hedonisme dan semacamnya, yang semuanya mengarah pada sikap "anti sosial", dan mungkin saja ini karena ketidaksiapan karakter pemuda dalam menghadapi era globalisasi. Dalam zaman yang terus menerus bergerak ke arah globalisasi yang semakin meluas ke seluruh pelosok dunia, ilmu pengetahuan merupakan senjata yang terbaik yang bisa digunakan untuk berkompetisi secara sehat dengan bangsa lain. Ini perlu agar kita mampu bertahan dalam era yang hampir tidak lagi memiliki batasan-batasan antara wilayah yang satu dengan wilayah yang lain. Dan untuk menguasai ilmu pengetahuan yang menjadi bekal untuk "bertempur" di era globalisasi, hanya akan bisa direngkuh dengan program pendidikan nasional yang kuat, yang memang tepat sasaran dalam membangun sumber daya manusia yang memiliki daya saing.

Pemuda adalah generasi penerus, calon pemimpin negara dan bangsa masa depan. Tanpa karakter yang kuat yang dimiliki para pemuda, maka akan memiliki resiko yang besar di masa yang akan datang bagi bangsa ini. Kita dapat melihat bahwa pergaulan dunia yang semakin tanpa batas, seperti ekonomi global dimana konsumen dan produsen (coorporations) tanpa mengenal batasbatas negara, setiap konsumen hanya mau membeli barang dan jasa dengan kualitas terbaik dan harga termurah dari manapun asalnya atau siapa pembuatnya. Oleh karena itu perlu dibangun karakter atau watak yang kuat di kalangan pemuda sebagai jaminan masa depan negara kita, Indonesia Raya.

\section{Epilog: Akhir Kata}

Berbagai aksi dan peranan pemuda dalam berbagai termin sejarah semakin memperkokoh keberadaan pemuda dalam menciptakan sebuah perubahan. Berbagai perubahan yang terjadi di negeri ini menempatkan pemuda sebagai aktor utamanya. Tidak bisa dipungkiri tentang peranan pemuda sebagai pencipta perubahan, bahkan rekam historis sekalipun. Idealisme, kemauan yang kuat dan konsistensi dalam bergerak menjadi amunisi positif untuk mewujudkan ide dan cita-citanya. Kekuatan dan keinginan yang kuat untuk merubah suatu kondisi dapat mengilhami orang lain untuk senantiasa optimis dan produktif. 
Perubahan menjadi indikator penting bagi keberhasilan pemuda dalam setiap gerakan-gerakan sosial yang dilakukannya. Perubahan seolah dianggap sebagai harga mati untuk senantiasa diwujudkan. Seperti ungkapan bijak yang menyatakan bahwa, "Tidak ada yang abadi di dunia ini selain perubahan itu sendiri". Pemuda pun menyadari bahwa dalam rangka menciptakan sebuah perubahan membutuhkan sesuatu yang harus dikorbankan. Artinya, pengorbanan menjadi perihal yang mutlak diperlukan untuk menciptakan kondisi yang berubah. Sebagai contoh misalnya, seorang pelajar yang ingin mendapatkan prestasi terbaik, maka dia harus mengorbankan waktunya untuk belajar dan mempersiapkan diri sebaik mungkin; mengorbankan egonya untuk tidak bermalas-malasan dan membuang waktu secara sia-sia, dan sebagainya. Maka tidak salah apabila Bung Karno pernah berujar, "Beri aku sepuluh pemuda, maka aku akan mengguncang dunia".

\section{Daftar Pustaka}

Akbar, Ali Ibrahim. 2007. Teori Soft Skill dalam Mencapai Keberhasilah Hidup. Jakarta: Prestasi Pustaka

Arifin, M. 1999. Ilmu Pendidikan Islam: Suatu Tinjauan Teoritis dan Praktis Berdasarkan Pendekatan Interdisipliner. Jakarta: Bumi Aksara

Arifin, Syamsul. 2000. Merambah Jalan Baru Dalam Beragama.Yogyakarta: Ittiqa' Press

Buchori, Mochtar. 2007. Menggugat Sistem Pendidikan; paradigma pendekatan holistic.Jakarta: Rajawali Press

Buku Induk Kebijakan Nasional Pembangunan Karakter Bangsa 2010-2025

Kusmiati Dkk. 2005. Dasar-Dasar Perilaku. Jakarta: Pusdiknakes

Pemerintah Republik Indonesia. 2005. Undang-Undang Sisdiknas (Sistem Pendidikan Nasional) 2003 (UU RI No. 20 Th. 2003).Jakarta: Sinar Grafika, 